\title{
Evaluating the Quality of Final Examination Question Paper in Engineering Education
}

\author{
Dr A M Abirami ${ }^{1}$, Dr M Palaninatha Raja ${ }^{2}$ \\ ${ }^{1}$ Department of Information Technology, Thiagarajar College of Engineering, Madurai \\ ${ }^{2}$ Department of Mechatronics, Thiagarajar College of Engineering, Madurai \\ 1abiramiam@tce.edu \\ ${ }^{2}$ pnatharaja@tce.edu
}

\begin{abstract}
In recent years, there has been a downtrend in the pass percentage of UG Engineering Mathematics papers among students. Students find it difficult to score pass marks in the subject in the recent batches. Factors like lack of understanding in basic concepts, lack of quality of teaching, lack of quality in question papers, strict evaluation, and so on may be related to poor performance of students. Hence, it becomes necessary to examine the nature of final examination question papers, especially for the maths courses. It is essential to assess the type of questions asked in the examinations using the statistical techniques and measures. In this paper, the descriptive study has been made to evaluate the quality of question papers of Mathematics with the result data.
\end{abstract}

Keywords: Engineering Mathematics, Item Analysis, Difficulty Index, Discrimination Index, Student Performance, Question Paper Quality

\section{Introduction}

According to the article published in press (https://timesofindia.indiatimes.com/city/chennai/toughmaths-only-25-1st-year-engineering-students-in-tamilnadu-clear-exams/articleshow/69420474.cms), only one in four first year students cleared all subjects in TamilNadu Engineering affiliated Colleges. It is equivalent to $25 \%$ of students passed all subjects for the year 2019. When Engineering Mathematics subject is considered, the pass percentage has come down to $31 \%$ in the year 2019, when compared with the previous year which was more than $40 \%$. However, the pass percentage of Engineering Physics and Chemistry was slightly better with $55 \%$ and $68 \%$ respectively.

Some Faculty members admitted that the students were lack in understanding the basic mathematical concepts of their Higher Secondary Education syllabus. Engineering teachers have expressed their concern and mismatch between the school and college education.

\section{Corresponding Author}

A M Abirami, Dept. of Information Technology, Thiagarajar College of Engineering, Madurai abiramiam@tce.edu

Students with $>90 \%$ score in their school exams also find difficult in scoring good marks in college education. Professors expected the changes in school education so as to give strong foundation in basic concepts of mathematics and science.

This situation motivates to examine the student performance in Engineering courses especially in mathematical courses. Arthur (2010) analysed final examination papers and observed that there were more Lower Order Thinking Skills (LOTS) questions and recommended for Higher Order Thinking Skills (HOTS) for various academic levels. Ajithkumar (2011) evaluated the quality of examination by recommending the Quality parameters and their level of presence in question papers through different student groups. Kashefi et. al. (2012) observed that both students and lecturers felt obstacles in imagining and visualizing the mathematical problems which ultimately resulted in poor results. Their study recommended Creative Problem Solving tools and techniques along with Active Learning Strategies for teaching and learning mathematical concepts. Ganeshkumar et. al. (2013) analysed question papers of two prominent institutions of India and United States. The team found that questions set in India had slight edge over the questions set in US institutions in HOTS domain.

Sowmya et. al. (2015) studied a set of question papers of Engineering programmes and explored the faculty awareness of Bloom's taxonomy in the cognitive domain and the possibility of achieving Higher Order Thinking Skills (HOTS) through examinations. Gul-Ar et. al. (2015) used item analysis technique for analysing essay type questions given in summative examination of medical college students. Serpil et. al. (2016) used statistical measures like difficulty and discrimination indices for analysing multiple choice questions for Open and Distance Learning context. Abubakar et. al (2017) analysed the various causes and effects for reduction in the student registration for advanced mathematics courses like 
Engineering Mathematics, Numerical Methods, and Statistics. The team recommended the local universities to involve in bridging the gap between the higher secondary and university education. Jain et. al. (2018) recommended guidelines for setting the question papers with easy, medium and difficulty levels, thereby ensuring that all types of learners would get minimum pass marks in the examinations. Himmah et. al. (2019) done a descriptive study on final examination mathematical question papers and observed that most of the questions were at Understand level of Bloom's taxonomy and only $10 \%$ of questions were at HOTS level.

From the literature review, it is found that most of research focussed on examining the final examinations questions in respect of bloom's taxonomy in cognitive domain or done item level analysis for evaluating the quality of question papers. To our knowledge, limited research was done for assessing the quality of engineering programmes' question papers using statistical techniques along with the students' performance. The key research questions framed are:

Does the quality of question paper have an impact on the results of end semester examinations? What are the various attributes that the question setter need to be aware of while setting the question papers?

This paper focuses on evaluating the quality of Engineering Mathematics courses of different Under Graduate (UG) Engineering programmes. The rest of the paper is organized as follows: section 2 describes the proposed methodology, section 3 discusses the results and section 4 concludes the paper.

\section{Methodology}

This paper focuses on evaluating the end semester question paper of Engineering Mathematics of different UG programmes. The following Research Objective (RO) is identified in order to carry out this study:

to set the range of values for different quality attributes for the question paper so as to have the moderate level of question paper.

The proposed methodology uses the Descriptive Analysis on the result data of different maths courses along with item analysis measures like difficulty and discrimination indices. Finally it suggests whether the question paper can be accepted, improved or rejected. This feedback is given to question setter by the Head of the Department, which helps the Faculty to maintain the moderate level while setting the question paper. The different steps are depicted in Fig. 1.

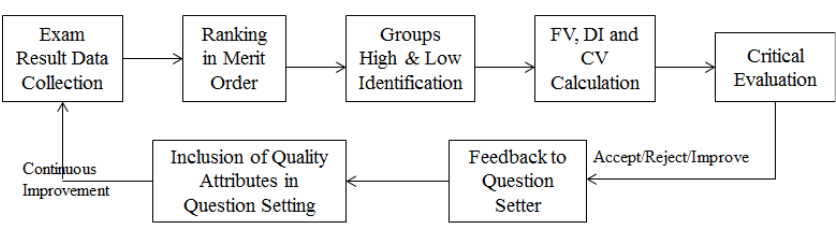

Fig 1. Proposed Methodology for determining Quality of Question Paper Difficulty Index or Facility value (FV) is the index for measuring the easiness or difficulty of a question paper. It is the percentage of students who have correctly answered and it varies from 0 to $100 \%$. Greater this value, easier the question paper is; and vice versa. Generally, if FV is 30 $70 \%$, it can be an "acceptable" question, if $50-60 \%$, it can be a "reliable" question.

Discrimination Index (DI) is the indicator showing how significantly the question paper discriminates between "high" and "low" performing students. It varies from -1 to +1 . Higher this value, the more would distinguish between high and low performers. The question paper is categorized as "excellent", if DI is greater than 35\%, as "good" question, if DI is 25 - $34 \%$; the question paper has to be revised, if DI is $15-24 \%$ and it can be discarded if DI is less than $15 \%$.

The coefficient of variation $(\mathrm{CV})$ is a measure of relative variability. It is the ratio of the standard deviation $(\sigma)$ to the mean $(\mu)$. It is a useful statistical measure for comparing the degree of variation from one data series to another, even if the means are drastically different from one another. If coefficient of variation is larger, then the level of dispersion around the mean is greater.

FV and DI are explained by the formulae:

Facility Value $(\mathrm{FV})=(\mathrm{H}+\mathrm{L}) /\left(2 * \mathrm{~N}^{*} \mathrm{M}\right)$

Discrimination Index DI $=(\mathrm{H}-\mathrm{L}) /(\mathrm{N} * \mathrm{M})$

where $\mathrm{H}$ is the number of top $27 \%$ students, $\mathrm{L}$ is the number of lower $27 \%$ students, $\mathrm{N}$ Is the total number of students in both the groups, $\mathrm{M}$ is the maximum mark of a question paper.

According to Das Mandal, the quality of question paper is categorized using FV and DI values as shown in Table 1.

Table 1.Evaluation Category of Question Paper

\begin{tabular}{|l|c|c|c|}
\hline DI $\backslash$ FV & $<\mathbf{0 . 3}$ & $\mathbf{0 . 3} \mathbf{- 0 . 6}$ & $>\mathbf{0 . 6}$ \\
\hline$<\mathbf{0 . 2}$ & Reject & Reject & Reject \\
\hline $\mathbf{0 . 2}-\mathbf{0 . 3}$ & Difficult & Improve & Easy \\
\hline $\mathbf{0 . 3}-\mathbf{0 . 4}$ & Improve & Accept & Improve \\
\hline $\mathbf{> 0 . 4}$ & Accept & Accept & Accept \\
\hline
\end{tabular}

\section{Results and Discussions}

The proposed methodology used the end semester marks of all students who appeared for the examinations. Data of two different batches (2014 and 2015 admitted) of students for six different UG programmes collected and studied. The different UG programmes include Civil Engineering, Mechanical Engineering, Electrical and Electronics Engineering, Electronics and Communication Engineering, Computer Science and Engineering, and Information Technology. The syllabus is common for semester 1 course across all programmes; the syllabus for semester 2 is customized to the specific requirements of the engineering disciplines. However, the two batches of the programme have the same syllabus and there is no difference in content and assessment pattern. 
The end semester marks of all students are ranked course/ discipline wise and top $27 \%$, lower $27 \%$ groups are identified. The following Tables 2 (a) and 2 (b) show the descriptive study on the marks for the Semester 1 and Semester 2 Engineering Mathematics courses of two batches of six different programmes.

Table 2 (a). Descriptive Analysis on Result Data of Engineering Mathematics Courses

\begin{tabular}{|c|c|c|c|c|c|c|c|c|c|}
\hline Sem & Course & Batch & Appeared & Pass & Fail & $\begin{array}{l}\text { Max. } \\
\text { Mark }\end{array}$ & $\begin{array}{l}\text { High } \\
\text { Score }\end{array}$ & $\begin{array}{l}\text { Low } \\
\text { Score }\end{array}$ & $\begin{array}{l}<20 \% \\
\text { Marks }\end{array}$ \\
\hline \multirow{2}{*}{ Sem -1} & \multirow{2}{*}{$\begin{array}{c}\text { Course_11 } \\
\text { (Common } \\
\text { Course) }\end{array}$} & Batch 1 & 709 & 664 & 45 & 50 & 50 & 2 & 12 \\
\hline & & Batch 2 & 700 & 626 & 74 & 50 & 50 & 1 & 18 \\
\hline \multirow{12}{*}{ Sem -2} & \multirow{2}{*}{$\begin{array}{c}\text { Course_21 } \\
\text { (Programme 1) }\end{array}$} & Batch 1 & 116 & 80 & 36 & 50 & 46 & 1 & 12 \\
\hline & & Batch 2 & 113 & 61 & 52 & 50 & 42 & 1 & 21 \\
\hline & \multirow{2}{*}{$\begin{array}{c}\text { Course_22 } \\
\text { (Programme 2) }\end{array}$} & Batch 1 & 114 & 95 & 19 & 50 & 41 & 3 & 4 \\
\hline & & Batch 2 & 116 & 90 & 26 & 50 & 43 & 2 & 9 \\
\hline & \multirow{2}{*}{$\begin{array}{c}\text { Course_23 } \\
\text { (Programme 3) }\end{array}$} & Batch 1 & 120 & 94 & 26 & 50 & 47 & 3 & 8 \\
\hline & & Batch 2 & 116 & 93 & 23 & 50 & 44 & 5 & 6 \\
\hline & \multirow{2}{*}{$\begin{array}{c}\text { Course_24 } \\
\text { (Programme 4) }\end{array}$} & Batch 1 & 120 & 99 & 21 & 50 & 49 & 4 & 2 \\
\hline & & Batch 2 & 115 & 100 & 15 & 50 & 45 & 9 & 1 \\
\hline & \multirow{2}{*}{$\begin{array}{c}\text { Course_25 } \\
\text { (Programme 5) }\end{array}$} & Batch 1 & 120 & 110 & 10 & 50 & 50 & 8 & 1 \\
\hline & & Batch 2 & 120 & 103 & 17 & 50 & 49 & 4 & 9 \\
\hline & \multirow{2}{*}{$\begin{array}{c}\text { Course_26 } \\
\text { (Programme 6) }\end{array}$} & Batch 1 & 114 & 89 & 25 & 50 & 47 & 1 & 4 \\
\hline & & Batch 2 & 114 & 59 & 55 & 50 & 45 & 1 & 11 \\
\hline
\end{tabular}

Table 2 (b). Descriptive Analysis on Result Data of Engineering Mathematics Courses

\begin{tabular}{|c|c|c|c|c|c|c|c|c|c|c|}
\hline Sem & Course & Batch & Mean & Median & Mode & Range & $\begin{array}{l}\text { Std. } \\
\text { Dev }\end{array}$ & FV & DI & $\begin{array}{c}\text { CV }= \\
\text { SD /Mean }\end{array}$ \\
\hline \multirow{2}{*}{ Sem - 1} & \multirow{2}{*}{$\begin{array}{c}\text { Course_11 } \\
\text { (Common } \\
\text { Course) }\end{array}$} & Batch 1 & 36.34 & 38 & 25 & 48 & 9.34 & 0.7 & 0.44 & 0.26 \\
\hline & & Batch 2 & 34.49 & 36 & 25 & 49 & 10.47 & 0.67 & 0.5 & 0.30 \\
\hline \multirow{11}{*}{ Sem - 2} & \multirow{2}{*}{$\begin{array}{c}\text { Course_21 } \\
\text { (Programme 1) }\end{array}$} & Batch 1 & 24.63 & 26 & 25 & 45 & 10.25 & 0.47 & 0.5 & 0.42 \\
\hline & & Batch 2 & 19.8 & 25 & 25 & 41 & 9.41 & 0.37 & 0.45 & 0.48 \\
\hline & \multirow{2}{*}{$\begin{array}{c}\text { Course_22 } \\
\text { (Programme 2) }\end{array}$} & Batch 1 & 28.96 & 31 & 33 & 38 & 8.31 & 0.55 & 0.38 & 0.29 \\
\hline & & Batch 2 & 27.08 & 27 & 25 & 41 & 9.33 & 0.54 & 0.42 & 0.34 \\
\hline & \multirow{2}{*}{$\begin{array}{c}\text { Course_23 } \\
\text { (Programme 3) }\end{array}$} & Batch 1 & 29.56 & 30.5 & 25 & 44 & 11.08 & 0.57 & 0.54 & 0.37 \\
\hline & & Batch 2 & 28.09 & 29.5 & 25 & 39 & 8.83 & 0.55 & 0.41 & 0.31 \\
\hline & \multirow{2}{*}{$\begin{array}{c}\text { Course_24 } \\
\text { (Programme 4) }\end{array}$} & Batch 1 & 31.43 & 32 & 25 & 45 & 10.08 & 0.63 & 0.49 & 0.32 \\
\hline & & Batch 2 & 28.77 & 28 & 25 & 36 & 7.36 & 0.58 & 0.36 & 0.26 \\
\hline & \multirow{2}{*}{$\begin{array}{c}\text { Course_25 } \\
\text { (Programme 5) }\end{array}$} & Batch 1 & 36.5 & 40 & 47 & 42 & 10.11 & 0.7 & 0.48 & 0.28 \\
\hline & & Batch 2 & 30.08 & 30.5 & 27 & 45 & 10.51 & 0.59 & 0.48 & 0.35 \\
\hline & $\begin{array}{c}\text { Course_26 } \\
\text { (Programme 6) }\end{array}$ & Batch 1 & 28.42 & 29.5 & 25 & 46 & 10.16 & 0.55 & 0.49 & 0.36 \\
\hline
\end{tabular}




\begin{tabular}{|l|l|l|l|l|l|l|l|l|l|l|} 
& Batch 2 & 21.72 & 25 & 25 & 44 & 9.64 & 0.44 & 0.47 & 0.44 \\
\hline
\end{tabular}

According to Table 1, the question paper of the course Course_21/Batch2 can be accepted $(F V=0.37, D I=0.45$ in Table 2(b)). However, there was $46 \%$ failure in this course, as shown in Table 2(a). In order to determine the Quality of question paper, the measure $\mathrm{CV}$ has also to be used along with difficulty and discrimination indices. For the Course_21, the value of CV is 0.48 which is very close to 0.5 . So we can classify this question paper as "Difficult". The mean, median and mode values for this course are 19.8, 25 and 25 respectively. Mean value is lesser than $50 \%$ of total score and the number of students scored 25 out of 50 is more, as shown in Table 2(b). Median and mode take the value of 25 , which says that most of students scored $50 \%$ of marks. Though the standard deviation is less, it does not help in categorizing quality of question paper. The measure of CV (0.48) tells that the question paper is very difficult, as shown in Table 2(b).

The measure of $\mathrm{CV}$ is useful in categorizing the question paper. It is evident from the Table 2(b) for the Course_25/Batch1. The question paper of this course is classified as "Very Easy", as its $\mathrm{FV}=0.7, \mathrm{DI}=0.48$ and $\mathrm{CV}=0.28$. The mean, median, and the mode values for this course is 36.5, 40 and 47 respectively, as shown in Table 2(b). These values also support that the question paper is "Very Easy", and the mean is greater than $50 \%$ of total score. Mode value specifies that more number of students scored 40 marks out of 50 for the course Course_25/Batch1. The difference between maximum and minimum marks is 42, as shown in Table 2(a), which says that the question paper is easy.

Table 3 shows the FV, DI and CV values of all 6 programmes for two different batches, using pass $\%$ and failure \%, ordered by the Failure percentage.

Table 3. Quality Parameters with Result Analysis

\begin{tabular}{|l|c|c|c|c|c|c|c|}
\hline Course & Batch & $\begin{array}{c}\text { Total } \\
\text { Stude }\end{array}$ & $\begin{array}{c}\text { Pass } \\
\text { nts }\end{array}$ & $\begin{array}{c}\text { Fail } \\
\text { \% }\end{array}$ & FV & DI & CV \\
\hline Course_25 & Batch 1 & 120 & 92 & $\mathbf{8}$ & 0.7 & 0.48 & $\mathbf{0 . 2 8}$ \\
\hline Course_24 & Batch 2 & 115 & 87 & 13 & 0.58 & 0.36 & 0.26 \\
\hline Course_25 & Batch 2 & 120 & 86 & 14 & 0.59 & 0.48 & 0.35 \\
\hline Course_22 & Batch 1 & 114 & 83 & 17 & 0.55 & 0.38 & 0.29 \\
\hline Course_24 & Batch 1 & 120 & 83 & 18 & 0.63 & 0.49 & 0.32 \\
\hline Course_23 & Batch 2 & 116 & 80 & 20 & 0.55 & 0.41 & 0.31 \\
\hline Course_22 & Batch 2 & 116 & 78 & 22 & 0.54 & 0.42 & 0.34 \\
\hline Course_23 & Batch 1 & 120 & 78 & 22 & 0.57 & 0.54 & 0.37 \\
\hline Course_26 & Batch 1 & 114 & 78 & 22 & 0.55 & 0.49 & 0.36 \\
\hline Course_21 & Batch 1 & 116 & 69 & 31 & 0.47 & 0.5 & 0.42 \\
\hline
\end{tabular}

\begin{tabular}{|l|c|c|c|c|c|c|c|} 
Course_21 & Batch 2 & 113 & 54 & $\mathbf{4 6}$ & 0.37 & 0.45 & $\mathbf{0 . 4 8}$ \\
\hline Course_26 & Batch 2 & 114 & 52 & $\mathbf{4 8}$ & 0.44 & 0.47 & $\mathbf{0 . 4 4}$ \\
\hline
\end{tabular}

Fig. 2 shows the facility value of question paper and the corresponding percentage of failures. It shows that $\%$ of failures decreases with the increase in facility value.

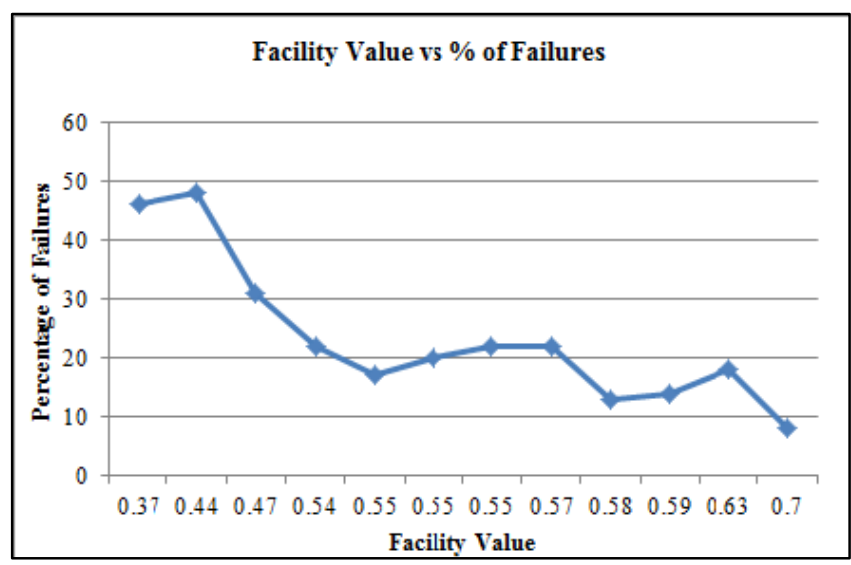

Fig. 2 Facility Value vs Percentage of Failures

Fig. 3 shows the necessary value for these quality parameters for a question paper. It is evident that $\%$ of failures increases with the decrease in Facility Value (FV). However, the value of Discriminator Index (DI) shows the clear distinguish between high and low performing students.

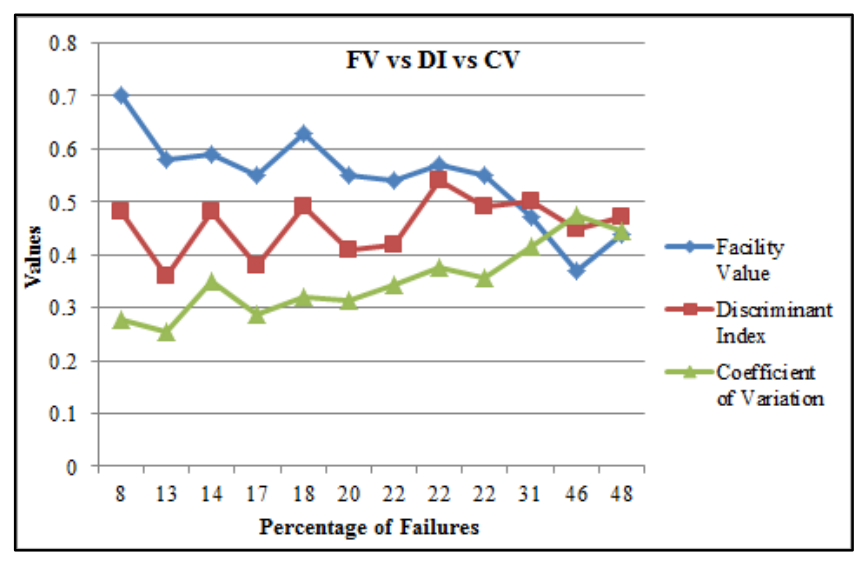

Fig. 3 Quality parameter values vs Percentage of Failures

Fig. 3 shows the $\%$ of failures increases with the increase in the $\mathrm{CV}$ value. It is obvious that there exists more variation in the marks of the students by having larger standard deviation $(\sigma)$ value, hence the increase in CV value. The question setter has to remember these parameter and their optimum values, so that the failure count can be reduced in the end semester examinations.

The qualitative analysis carried out on the results of end semester examinations of various Engineering Mathematics 
courses clearly states that the quality attributes followed in the question papers have direct impact on students' performance. Thus, the research objective (RO) is addressed by recommending the following guidelines for setting the Quality Question Papers with range of values for quality attributes, as shown in Table 4. The Accept category, proposed by Das Mandal is slightly modified by including the measure $\mathrm{CV}$. The question paper has all the satisfied quality attributes (Category $=$ Accept), if it possess the following values: $\mathrm{FV}$ is 0.3 to 0.6 and DI is 0.3 to 0.4 and $\mathrm{CV}<0.4$; else it may fall under Difficult Category. Similarly, the question paper falls under Accept Category, if FV is $>0.6$, and $\mathrm{DI}$ is $>0.4$, and $\mathrm{CV}<0.4$; else it may fall under Improve Category. If FV is $>0.6$ and $\mathrm{CV}$ is $<0.4$, the question paper is "Very Easy" and needs to be improved. If FV is $0.3-0.6$ and $\mathrm{CV}$ is $>0.4$, the question paper is "Difficult" and needs to be improved. It ensures that the question paper is set at the moderate level.

Table 4. Guidelines for Quality Question Paper

\begin{tabular}{|c|c|c|c|c|c|c|}
\hline $\mathrm{DI} \backslash \mathrm{FV}$ & \multicolumn{2}{|c|}{$<0.3$} & \multicolumn{2}{|c|}{$0.3-0.6$} & \multicolumn{2}{|c|}{$>0.6$} \\
\hline$<0.2$ & \multicolumn{2}{|c|}{$\mathrm{R}$} & \multicolumn{2}{|c|}{$\mathrm{R}$} & \multicolumn{2}{|c|}{$\mathrm{R}$} \\
\hline $0.2-0.3$ & \multicolumn{2}{|c|}{ D } & \multicolumn{2}{|c|}{ I } & \multicolumn{2}{|c|}{$\mathrm{E}$} \\
\hline $0.3-0.4$ & \multicolumn{2}{|c|}{ I } & $\begin{array}{c}\mathrm{CV}>0.4 \\
\mathrm{D}\end{array}$ & $\begin{array}{c}\mathrm{CV}<0.4 \\
\mathrm{~A}\end{array}$ & \multicolumn{2}{|c|}{ I } \\
\hline$>0.4$ & $\begin{array}{c}\text { CV > } \\
0.4 \\
\text { I }\end{array}$ & $\begin{array}{c}\text { CV }< \\
0.4 \\
\text { A }\end{array}$ & $\begin{array}{c}\text { CV > } \\
0.4 \\
\text { I }\end{array}$ & $\begin{array}{c}\text { CV }< \\
0.4 \\
\text { A }\end{array}$ & $\begin{array}{c}\text { CV > } \\
0.4 \\
\text { I } \\
\end{array}$ & $\begin{array}{c}\mathrm{CV}< \\
0.4 \\
\mathrm{~A}\end{array}$ \\
\hline
\end{tabular}

The legends include: R- Reject, D - Difficult, I - Improve, A - Accept, E - Easy. Table 4

\section{Conclusion}

Engineering students feel that the Engineering Mathematics is the challenging course and getting pass marks in the first attempt is the hardest task. There could be various reasons for the poor results in the end semester examinations. As part of Quality Assurance activity, it becomes necessary to assess the quality of question paper with the statistical measures like facility value, discriminator index and coefficient of variation along with the result data. It would help the question setters to give the idea for having improved students' performance in the course. This type of research enables the Institute to set up Question Paper Standards for the entire curriculum.

Future work includes analysis on the quality of question papers of continuous assessment tests along with their results, aligned with the results of end semester examinations. Student feedback on the difficulty level of the questions immediately after their examinations may also be considered for assessing the quality of question papers.

\section{Acknowledgement}

We acknowledge our Institute Thiagarajar College of Engineering Madurai for carrying out this detailed analysis on the result data. The work was internally supported by IQAC division of the Institute.

\section{References}

Adam Hayes, "Coefficient of Variation", https://www.investopedia.com/terms/c/coefficientofvariatio n.asp, 2019 [accessed on Aug 2019].

Ajithkumar, N. S. (2011) Criteria for Evaluating the Quality of a Question Paper. Journal of Technical Education and Training, 3(1), 59-64.

Arthur, J. S. (2010) Evaluation of Final Examination Papers in Engineering: a case study using Bloom's Taxonomy, IEEE Transactions on Education, 53(2), 257-264.

Das Mandal, S. K. Overview of Assessment and Evaluation, Centre for Educational Technology, IIT Kharagpur. [accessed on June 2019]

Ganeshkumar, N., Mohanram, P. and Rudramoorthy, R. (2013) A Case study on Quality of Setting up Engineering Question Papers, International Journal of Educational Science and Research, 3 (1), 145-152.

Gul-Ar, N. K., Nazia, I. and Abdul, Q. K. (2015) Using Item analysis on essay type questions given in summative examination of medical college students: facility value, discrimination index, International Journal of Research in Medical Sciences, 3(1), 178-182.

Hasan, A. B., Abdul, F. A., and Selamat, Z. (2017) Effectiveness of mathematics education in secondary schoolsto meet the local universities missions in producing qualityengineering and science undergraduates, IOP Conference Series: Materials Science and Engineering, 298. Himmah, W. I, Nayazik, A and Setyawan, F. (2019) Revised Bloom's taxonomy to analyze the final mathematics examination problems in Junior High School, Journal of Physics Conference Series, 1188.

Jain, N. K., Rachana Garg and Sahu, A. K. (2018) Guidelines for setting Good Quality Question Papers, Delhi Technological University [accessed on Nov 2019]

Kashefi, H., Ismail, Z. and Yusof, Y. M. (2012) Engineering Mathematics Obstacles and Improvement: A comparative study of students and lecturers perspectives through creating problem solving, Proceedia Social and Behavioral Sciences, 56, 556-564.

Ragu Raman, A. (2019) 'Tough' maths: Only 25\% 1st year engineering students in TamilNadu clear exams,

http://timesofindia.indiatimes.com/articleshow/69420474.c ms?utm_source=contentofinterest\&utm_medium $=$ text $\&$ ut m_campaign $=$ cppst, [accessed on 2-Sept-2019]

Serpil, Neidet and Murat, D. S. (2016) Analysis of the Difficulty and Discrimination Indices of Multiple-Choice QuestionsAccording to Cognitive Levels in an Open and Distance Learning Context, The Turkish Online Journal of Educational Technology, 15(4), 16-24.

Sowmya, N. and Adithan, M. (2015) Analysis of Question Papers in Engineering Courses with Respect to Hots, American Journal of Engineering Education, 6 (1). 